\title{
PROPRIEDADES FÍSICAS E QUÍMICAS DO SOLO EM ÁREAS COM SISTEMAS PRODUTIVOS E MATA NA REGIÃO DA ZONA DA MATA MINEIRA ${ }^{(1)}$
}

\author{
Arley Figueiredo Portugal ${ }^{(2)}$, Oldair Del'Arco Vinhas Costa ${ }^{(3)} \&$ \\ Liovando Marciano da Costa ${ }^{(4)}$
}

\begin{abstract}
RESUMO
Tendo em vista o potencial de produção e a extensão de área que ocupam os Latossolos, é de grande interesse estabelecer sistemas de manejo que não modifiquem o solo de forma a comprometer sua sustentabilidade. Nesse sentido, avaliaram-se as alterações em propriedades físicas e químicas de um Latossolo sob diferentes sistemas agrícolas na Zona da Mata mineira. Foram avaliadas áreas sob laranja, cana, pastagem e mata: as de laranja e pastagem têm mais de 20 anos de uso; a de cana é anterior (100 anos). A cana é remanescente de uso histórico por aproximadamente 120 anos. A amostragem foi realizada em trincheiras, nas profundidades de 0,0 a 0,2 e 0,2 a $0,4 \mathrm{~m}$. Foram analisadas as características químicas: matéria orgânica do solo (MOS), $\mathrm{pH}$ em $\mathrm{H}_{2} \mathrm{O}, \mathrm{P}$ disponível, $\mathrm{Ca}^{2+}, \mathrm{Mg}^{2+}, \mathrm{K}^{+}$, $\mathrm{Al}^{3+}, \mathrm{H}+\mathrm{Al}$, soma de bases (SB), CTC efetiva e total (t) e saturação por bases (V), e P-remanescente. As características físicas analisadas foram: textura, densidade de partículas, densidade do solo, porosidade total, curva de retenção de água, resistência do solo à penetração e estabilidade de agregados em água, bem como a relação capacidade de campo/porosidade total (CC/PT). Para análise dos dados, consideraram-se os usos agrícolas como tratamentos, em um delineamento inteiramente casualizado, na análise de variância de cada profundidade separadamente. Os sistemas agrícolas com laranjeira e canavial melhoraram a condição química do solo, aumentando os teores de nutrientes e diminuindo o $\mathrm{Al}^{3+}$ do complexo de troca, porém apresentaram redução dos teores de MOS e níveis intermediários de degradação física. $\mathrm{O}$ sistema com pastagem apresentou baixa
\end{abstract}

\footnotetext{
(1) Trabalho apresentado na XVI Reunião Brasileira de Manejo e Conservação do Solo e da Água. Recebido para publicação em julho de 2008 e aprovado em janeiro de 2010.

(2) Analista da Embrapa Milho e Sorgo. Rod. 424, Km 45, Caixa Posta 151, CEP 35702-098 Sete Lagoas (MG). E-mail: arley@cnpms.embrapa.br

(3) Professor Adjunto da Universidade Federal do Recôncavo da Bahia - UFRB. Campus Universitário de Cruz das Almas. CEP 44380-000. Cruz das Almas (BA). E-mail: oldairvinhas@hotmail.com.br

(4) Professor do Departamento de Solos, UFV. Av PH Rolfs s/n, CEP 36570-000 Viçosa (MG). Bolsista do CNPq. E-mail: liovandomc@yahoo.com.br
} 
fertilidade e caráter distrófico, redução acentuada do teor de MOS e degradação física mais avançada, evidenciada pelo aumento da densidade do solo e resistência à penetração, bem como redução da porosidade total e da estabilidade de agregados.

Termos de indexação: Latossolo, uso e manejo do solo, degradação do solo.

\author{
SUMMARY: PHYSICAL AND CHEMICAL PROPERTIES OF A SOIL UNDER \\ DIFFERENT PRODUCTION SYSTEMS AND FOREST IN THE \\ ZONA DA MATA REGION OF MINAS GERAIS STATE (BRAZIL)
}

\begin{abstract}
Knowledge on chemical and physical soil properties provides the theoretical basis for a sustainable planning of natural resources. This study evaluated the alteration of chemical and physical soil characteristics in a Haplustox in the Zona da Mata region of the State of Minas Gerais (Brazil), under different crop systems. The systems evaluated were orange orchards, sugar-cane plantation, pasture and forest, as control. Orange orchards and pasture had been established more than 20 years before, both in succession to sugar-cane, previously grown for over a century. The sugar cane is a reminiscent of crop cultivated for more than 120 years. Soil was sampled in pits at depths of 0.0-0.2 and 0.2-0.4 m. The following chemical properties were evaluated: soil organic matter (MOS); $\mathrm{pH}$ in $\mathrm{H}_{2} \mathrm{O}, \mathrm{P}, \mathrm{Ca}^{2+}, \mathrm{Mg}^{2+}, \mathrm{K}$, $A l^{3+}, H+A l, S B, C T C(t)$, and $V$, and the physical properties: texture, soil density, particle density, porosity, water retention curve, soil penetration resistance, and aggregate stability, as well as the ratio field capacity/soil total porosity. In the data evaluation, the crop systems represented treatments in a completely random design, and analysis of variance was performed for each depth separately. In the crop systems orange and sugar cane the chemical properties were improved, raising the nutrient levels and reducing the exchangeable $\mathrm{Al}^{3+}$, level but SOM was reduced and intermediate levels of physical degradation were observed. In the pasture system, low fertility and a dystrophic character were Stated, reduced SOM and high physical degradation, indicated by increased soil density and soil penetration resistance, and by lower porosity and aggregate stability.
\end{abstract}

Index terms: Oxisol, soil use and management, soil degradation.

\section{INTRODUÇÃO}

Os Latossolos pertencem a uma classe de solos de grande importância, tendo em vista o seu potencial de produção e a extensão de área que ocupam; assim, estabelecer sistemas de manejo que objetivem a sustentabilidade desses solos é de grande interesse, especialmente no domínio de Mares de Morros, onde sua presença está associada aos topos dos morros (Abrahão et al., 2000), sendo áreas bastante utilizadas para produção agrícola nesses ambientes (Jose, 1982; Rezende \& Resende, 1996; Portugal et al., 2008).

Segundo Rezende \& Resende (1996) e Abrahão et al. (2000), os solos nos Mares de Morros geralmente são pobres, tendendo a distróficos e álicos, na maior parte, devido ao profundo manto de intemperismo, com quase ausência de minerais primários facilmente intemperizáveis e relevo acidentado, o que torna esses ecossistemas bastante vulneráveis quanto às perdas de nutrientes, pois estes são perdidos com facilidade e não há como serem recuperados naturalmente.
A remoção da cobertura vegetal natural e a implantação de atividades agropecuárias, devido às ações que envolvem as diferentes formas de uso e manejo, provocam desequilíbrio no ecossistema, uma vez que o manejo adotado influenciará os processos físicos, químicos e biológicos do solo, modificando suas propriedades químicas e físicas (Canellas et al., 2003; Rangel \& Silva, 2007; Costa et al., 2008). Essas modificações antrópicas do solo podem ser de caráter positivo ou negativo, isto é, tanto podem provocar melhoria em certas propriedades do solo, como também podem acelerar sua degradação, dependendo principalmente da natureza do solo, da espécie vegetal, do sistema de manejo usado e do tempo de exploração agrícola (Castro Filho et al., 1998; Rangel \& Silva, 2007; Salton et al., 2008; Costa et al., 2008; Carneiro et al., 2009).

A compactação do solo é um dos fatores limitantes à produção das culturas e é condicionada não só por fatores externos, especificamente por tipo, intensidade e frequência da pressão aplicada (Proffit et al., 1993; 
Lima et al., 2004), mas também por fatores internos, como: textura, estrutura, ciclos de umedecimento e secagem e densidade do solo (Oliveira et al., 1996; Islam \& Weil, 2000; Carneiro et al., 2009). Além da análise de densidade do solo, um dos indicadores da compactação é a resistência do solo à penetração, que descreve a resistência física que o solo oferece a algo que tenta se mover através dele, como uma raiz em crescimento ou uma ferramenta de cultivo (Pedrotti et al., 2001), e também outras propriedades físicas do solo alteradas pela compactação, como as características de retenção de água e a infiltração (Leão et al., 2004).

A estrutura apresenta grande influência nos ciclos de $\mathrm{C}$ e de nutrientes, na capacidade de receber, estocar e transmitir água, na difusão de gases, na penetração das raízes e na capacidade de resistir à erosão, que são fatores determinantes para o crescimento das plantas (Salton et al., 2008). Dessa forma, a estrutura do solo, geralmente avaliada pela distribuição e estabilidade dos agregados, tem sido proposta como um importante indicador da qualidade do solo (Oliveira et al., 1996; Castro Filho et al., 1998; Salton et al., 2008).

A avaliação das alterações ocorridas em propriedades dos solos em função do seu uso e manejo assume grande importância prática, uma vez que o entendimento das modificações ocorridas nas propriedades químicas e físicas, decorrentes do seu cultivo, pode fornecer elementos para produção em bases sustentáveis (Canellas et al., 2003; Rangel \& Silva, 2007; Costa et al., 2008; Carneiro et al., 2009). Assim, o presente trabalho teve por objetivo avaliar as alterações nas propriedades físicas e químicas de um Latossolo Vermelho-Amarelo distrófico sob diferentes sistemas agrícolas na Zona da Mata mineira.

\section{MATERIAL E MÉTODOS}

A área escolhida para o estudo está localizada no município de Visconde do Rio Branco, na Zona da Mata do Estado de Minas Gerais. O município possui temperatura média anual de $23,9^{\circ} \mathrm{C}$, com médias das máximas e mínimas de 31,9 e $16^{\circ} \mathrm{C}$, respectivamente. $\mathrm{O}$ índice pluviométrico anual no município é de $1.100 \mathrm{~mm}$, com as chuvas concentradas no período de outubro a março (SEBRAE, 2001), apresentando, de acordo com a classificação climática de Köppen, clima Cwa. Seu território possui relevo ondulado a forte ondulado, com altitude média de $350 \mathrm{~m}$, e pertence ao Domínio dos Mares de Morros (Ab'Saber, 1970). Em geral, nos Mares de Morros os solos são pobres, tendendo a ser distróficos e álicos na maior parte, com um profundo manto de intemperismo, que leva à quase ausência de minerais primários facilmente intemperizáveis e grande ocorrência de solos argilosos a muito argilosos (Rezende \& Resende, 1996).
O trabalho foi realizado em duas propriedades agrícolas vizinhas, localizadas uma nas coordenadas de $21^{\circ} 4^{\prime} 4^{\prime}$ "de latitude sul e $42^{\circ} 50$ ' 22 " de longitude e a outra em $21^{\circ} 3^{\prime}$ ' 43 "de latitude sul e $42^{\circ} 50$ ' 27 "de longitude W.Gr., situadas em áreas adjacentes localizadas no topo da paisagem, ocorrendo Latossolo Vermelho-Amarelo distrófico (Embrapa, 1999) em todas as áreas. Cada área representa um uso do solo, sendo eles canavial, pastagem, laranjeira e mata (referência). Anteriormente, as áreas com pastagem e laranjeira foram ocupadas por cana-de-açúcar, há aproximadamente 100 anos, segundo entrevista com os proprietários e seguindo a influência histórica da atividade canavieira no município (José, 1982). Os usos com laranjeira e pastagem são de 20 anos, enquanto a cana é um remanescente de uso histórico com a atividade canavieira. A área de mata é de aproximadamente 6 ha, sendo a amostragem realizada nas coordenadas $21^{\circ} 5^{\prime} 25$ "de latitude sul e $42^{\circ} 4^{\prime} 51^{\prime}$ de longitude W.Gr. A vegetação é composta de mata atlântica secundária, com fisionomia de Floresta Ombrófila Aberta (FOA), e não sofreu alterações antrópicas no período de ocupação com a cana, servindo, portanto, como referência para as características avaliadas.

Aárea com pastagem é de aproximadamente 20 ha, e a amostragem foi realizada nas coordenadas de $21^{\circ} 4^{\prime} 3$ "de latitude sul e $42^{\circ} 51^{\prime} 3$ " de longitude W.Gr. Nessa área tem-se o capim-braquiária (Brachiaria decumbens Stapf) e não há ocorrência de plantas espontâneas. A pastagem mostra sinais de degradação, com considerável área de solo exposto (estimativa de $30 \%$ do solo exposto). O manejo é inadequado, com superpastejo e uso contínuo da pastagem durante todo o ano. Não se utilizam corretivos químicos nesse solo e a produção de leite média é de $3 \mathrm{~L}$ dia-1/vaca, caracterizando um baixo nível tecnológico.

A área com laranjeira (Citrus sinensis (L.) Osbeck) é de aproximadamente $10 \mathrm{ha}$; a amostragem foi realizada nas coordenadas $21^{\circ} 3$ ' 37 "de latitude sul e $42^{\circ} 52$ ' 29 " de longitude W.Gr. Na implantação da laranjeira, foi realizada a calagem somente na cova (200 g de calcário dolomítico) e a cada dois anos, segundo análise de solo; na coleta das amostras já se fazia dois anos da aplicação do calcário $\left(1,75 \mathrm{t} \mathrm{ha}^{-1}\right)$. No plantio, foram colocados em torno de $10 \mathrm{~L}$ de esterco de curral por cova e $140 \mathrm{~kg} \mathrm{ha}^{-1}$ de superfosfato simples. Não foram feitas aração e gradagem na área, e utilizou-se o espaçamento de 7 x $4 \mathrm{~m}$. O controle de plantas espontâneas é feito utilizando glifosato, em pós-emergência na linha do plantio (4 $\left.\mathrm{L} \mathrm{ha}^{-1}\right)$; nas entrelinhas utiliza-se roçadeira tratorizada, três vezes ao ano, preservando a palhada na superfície. A adubação do pomar é realizada mediante análises do solo, utilizando comumente superfosfato simples (90 kg ha-1 ano $\left.^{-1}\right)$, sulfato de amônio e cloreto de potássio (715 kg ha-1 ano-1 de N-P $\mathrm{O}_{5}-\mathrm{K}_{2} \mathrm{O}$ (15-00-15)). Realiza-se a aplicação foliar de $\mathrm{Ca}^{2+}, \mathrm{Mg}^{2+}, \mathrm{Zn}, \mathrm{Mn}$ e $B$ três vezes por ano, e a de fungicidas, quando necessário. A produção de laranja é de 30 t ha-1 ano $^{-1}$. 
A área com cana (Saccharum officinarum L.) é de aproximadamente 5 ha, sendo a amostragem realizada nas coordenadas de $21^{\circ} 5^{\prime} 2$ "de latitude sul e $42^{\circ} 49^{\prime} 3$ " de longitude W.Gr., sendo um remanescente do uso histórico dessa cultura. $\mathrm{O}$ uso com a cana provocou grande degradação do solo da região Mares de Morro, devido ao relevo acentuado e à ausência de preocupação com práticas conservacionistas. Nos topos dos morros, onde ocorrem áreas mais planas, com Latossolo, a erosão e degradação foram menores que nas áreas mais íngremes. A cana encontrava-se em estádio fisiológico de maturação e com presença de invasora (braquiária). O sistema de colheita realizado é o manual com cana queimada. No plantio, foi realizada a correção com $2,00 \mathrm{t} \mathrm{ha}^{-1}$ de calcário dolomítico espalhado em área total e incorporado até $20 \mathrm{~cm}$, bem como aplicação de $400 \mathrm{~kg} \mathrm{ha}^{-1}$ de N-P $\mathrm{P}_{2} \mathrm{O}_{5^{-}}$ $\mathrm{K}_{2} \mathrm{O}(0-25-20)$ no sulco de plantio. A cobertura da soqueira foi feita com $300 \mathrm{~kg} \mathrm{ha}^{-1} \mathrm{ano}^{-1}$ de NPK (20-020), há um ano. A produção média é de $90 \mathrm{t} \mathrm{ha}^{-1}$. Tratores para colheita, adubação e demais práticas agrícolas necessárias à cultura foram utilizados na área.

As amostras foram coletadas nas profundidades de 0,0 a 0,2 e de 0,2 a $0,4 \mathrm{~m}$. Os diferentes usos do solo foram os tratamentos, e considerou-se o delineamento inteiramente casualizado na análise dos dados. Em cada uso, uma área de aproximadamente 1 ha foi dividida em três partes (parcelas), onde foi aberta uma trincheira para a amostragem de características físicas do solo, bem como realizadas amostras compostas (mistura de 20 amostras simples) para obtenção da terra fina seca ao ar (TFSA), obtendose três repetições para cada parâmetro físico e químico. Para determinar a resistência do solo à penetração, foram realizadas 10 repetições aleatórias dentro de cada uso. A resistência do solo à penetração foi determinada no mesmo dia em todos os sistemas, sendo retiradas amostras para determinação da umidade do solo na camada de 0 a $20 \mathrm{~cm}$ no momento da avaliação em cada sistema.

As determinações químicas realizadas foram: matéria orgânica do solo (MOS); $\mathrm{pH}$ em $\mathrm{H}_{2} \mathrm{O}$; teores de $\mathrm{Ca}^{2+}, \mathrm{Mg}^{2+}, \mathrm{K}^{+}, \mathrm{Al}^{3+}$ trocáveis; $\mathrm{P}$ disponível (Mehlich-1); acidez potencial $(\mathrm{H}+\mathrm{Al})$, soma de bases (SB); CTC efetiva (t); CTC total (T); saturação por bases (V), conforme Embrapa (1997); e P remanescente (Prem), segundo Alvarez V. et al. (1993).

Foram feitas as seguintes determinações físicas: textura, densidade de partículas, densidade do solo, porosidade total, retenção de água na capacidade de campo e no ponto de murcha permanente, realizadas segundo método descrito em Embrapa (1997). A resistência à penetração foi determinada por meio de um penetrômetro de impacto, sendo os cálculos realizados conforme Stolf (1991). Na estabilidade de agregados utilizou-se o método descrito por Embrapa (1997). A capacidade de água disponível (CAD) foi determinada subtraindo da água retida no solo sob tensão equivalente a $10 \mathrm{kPa}$ (capacidade de campo) a quantidade de água retida na tensão equivalente a $1.500 \mathrm{kPa}$ (ponto de murcha permanente), $\mathrm{em} \mathrm{m}^{3} \mathrm{~m}^{-3}$. Foi utilizada a tensão de $10 \mathrm{kPa}$ para representar a capacidade de campo (CC), com base em resultados obtidos por Reichardt (1988), que considera essa a melhor tensão para representar a CC em solos tropicais. Foi calculada a relação capacidade de campo/porosidade total (CC/PT), usando valores das variáveis supracitadas.

Os efeitos dos tratamentos (usos) sobre as propriedades químicas e físicas do solo foram testados por meio de análise de variância (ANOVA). Analisouse o efeito do uso do solo nas suas propriedades químicas e físicas em cada profundidade, separadamente. Quando as variáveis foram estatisticamente diferentes, as médias foram comparadas pelo teste de Tukey a $5 \%$.

\section{RESULTADOS E DISCUSSÃO}

\section{Atributos químicos}

Os valores dos atributos químicos do solo apresentaram variação significativa sob os usos mata, laranja, cana e pastagem, nas profundidades de $0,0 \mathrm{a}$ 0,2 e 0,2 a $0,4 \mathrm{~m}$ (Quadro 1). Os teores de $\mathrm{Al}^{3+}$ variaram significativamente entre os usos, com os maiores valores ocorrendo na mata $(1,80 \mathrm{e}$ $1,80 \mathrm{cmol}_{\mathrm{c}} \mathrm{dm}^{-3}$, de 0,0 a 0,2 e 0,2 a $0,4 \mathrm{~m}$, respectivamente) e os menores na cana $(0,60 \mathrm{e}$ $0,83 \mathrm{cmol}_{\mathrm{c}} \mathrm{dm}^{-3}$, de 0,0 a 0,2 e 0,2 a $0,4 \mathrm{~m}$, respectivamente), acompanhando as variações de $\mathrm{pH}$, já que $\mathrm{o} \mathrm{Al}^{3+}$ tóxico às plantas é reduzido à medida que o $\mathrm{pH}$ aumenta (Haynes \& Naidu, 1998; Alvarez V. et al., 1999; Sousa et al., 2007). Segundo a classificação de Alvarez V. et al. (1999), os teores de $\mathrm{Al}^{3+}$ variaram de muito baixo a muito alto.

Os valores de acidez potencial $(\mathrm{H}+\mathrm{Al})$ também variaram entre os usos, apresentando comportamento similar ao mostrado pelo $\mathrm{Al}^{3+}$, com os maiores valores observados na mata $\left(9,83\right.$ e $8,45 \mathrm{cmol}_{\mathrm{c}} \mathrm{dm}^{-3}$, de $0,0 \mathrm{a}$ 0,2 e 0,2 a $0,4 \mathrm{~m}$, respectivamente) e menores no canavial $\left(6,07\right.$ e $5,68 \mathrm{cmol}_{\mathrm{c}} \mathrm{dm}^{-3}$, de 0,0 a 0,2 e 0,2 a $0,4 \mathrm{~m}$, respectivamente) (Quadro 1). Os valores de $\mathrm{H}+\mathrm{Al}$ na área de laranjeiras foram maiores entre os usos agrícolas nas duas profundidades, o que não aconteceu com o $\mathrm{Al}^{3+}$, indicando que a diferença na acidez potencial nesse ambiente deve-se ao maior valor de H. Isso se explica pelo maior teor de matéria orgânica observado na laranjeira (Quadro 1), já que a matéria orgânica do solo apresenta vários grupos funcionais, especialmente os grupos carboxílicos e fenólicos, que podem liberar o H que irá compor os íons envolvidos na capacidade de troca de cátions do solo (CTC) (Fontes et al., 2001; Rangel \& Silva, 2007; Sousa et al., 2007). 
Quadro 1. Atributos químicos do Latossolo sob os usos com mata, laranja, cana-de-açúcar e pastagem, nas profundidades de 0,0 a 0,2 e 0,2 a $0,4 \mathrm{~m}$

\begin{tabular}{|c|c|c|c|c|c|}
\hline Atributo & Profundidade & Mata & Laranja & Cana & Pasto \\
\hline $\mathrm{pH}\left(\mathrm{H}_{2} \mathrm{O}\right)$ & $\begin{array}{c}\mathrm{m} \\
0,0-0,2 \\
0,2-0,4\end{array}$ & $\begin{array}{l}4,32 \mathrm{a} \\
4,30 \mathrm{a}\end{array}$ & $\begin{array}{l}4,79 \mathrm{~b} \\
4,62 \mathrm{~b}\end{array}$ & $\begin{array}{l}4,86 \mathrm{~b} \\
4,70 \mathrm{~b}\end{array}$ & $\begin{array}{l}4,49 \mathrm{a} \\
4,47 \mathrm{ab}\end{array}$ \\
\hline $\mathrm{P}\left(\mathrm{mg} \mathrm{dm} \mathrm{dm}^{-3}\right)$ & $\begin{array}{l}0,0-0,2 \\
0,2-0,4\end{array}$ & $\begin{array}{l}2,37 \mathrm{a} \\
1,06 \mathrm{a}\end{array}$ & $\begin{array}{l}6,45 \mathrm{~b} \\
2,76 \mathrm{~b}\end{array}$ & $\begin{array}{l}7,45 \mathrm{~b} \\
2,21 \mathrm{~b}\end{array}$ & $\begin{array}{l}3,28 \mathrm{a} \\
0,86 \mathrm{a}\end{array}$ \\
\hline $\mathrm{K}^{+}\left(\mathrm{mg} \mathrm{dm}{ }^{-3}\right)$ & $\begin{array}{l}0,0-0,2 \\
0,2-0,4\end{array}$ & $\begin{array}{l}24 \mathrm{a} \\
13 \mathrm{ab}\end{array}$ & $\begin{array}{l}76 \mathrm{c} \\
56 \mathrm{c}\end{array}$ & $\begin{array}{l}35 \mathrm{~b} \\
16 \mathrm{~b}\end{array}$ & $\begin{array}{l}24 \mathrm{a} \\
12 \mathrm{a}\end{array}$ \\
\hline $\mathrm{Ca}^{2+}\left(\mathrm{cmol}_{\mathrm{c}} \mathrm{dm}^{-3}\right)$ & $\begin{array}{l}0,0-0,2 \\
0,2-0,4\end{array}$ & $\begin{array}{l}0,21 \mathrm{a} \\
0,07 \mathrm{a}\end{array}$ & $\begin{array}{l}1,14 \mathrm{~b} \\
0,85 \mathrm{c}\end{array}$ & $\begin{array}{l}1,05 \mathrm{~b} \\
0,73 \mathrm{bc}\end{array}$ & $\begin{array}{l}0,38 \mathrm{a} \\
0,36 \mathrm{ab}\end{array}$ \\
\hline $\mathrm{Mg}^{2+}\left(\mathrm{cmol}_{c} \mathrm{dm}^{-3}\right)$ & $\begin{array}{l}0,0-0,2 \\
0,2-0,4\end{array}$ & $\begin{array}{l}0,20 \mathrm{a} \\
0,11 \mathrm{a}\end{array}$ & $\begin{array}{l}0,53 \mathrm{~b} \\
0,34 \mathrm{a}\end{array}$ & $\begin{array}{l}0,45 \mathrm{ab} \\
0,28 \mathrm{a}\end{array}$ & $\begin{array}{l}0,17 \mathrm{a} \\
0,11 \mathrm{a}\end{array}$ \\
\hline $\mathrm{Al}^{3+}\left(\mathrm{cmol}_{\mathrm{c}} \mathrm{dm}^{-3}\right)$ & $\begin{array}{l}0,0-0,2 \\
0,2-0,4\end{array}$ & $\begin{array}{l}1,80 \mathrm{~d} \\
1,80 \mathrm{c}\end{array}$ & $\begin{array}{l}0,96 \mathrm{~b} \\
1,44 \mathrm{~b}\end{array}$ & $\begin{array}{l}0,60 \mathrm{a} \\
0,83 \mathrm{a}\end{array}$ & $\begin{array}{l}1,32 \mathrm{c} \\
1,56 \mathrm{bc}\end{array}$ \\
\hline $\mathrm{H}+\mathrm{Al}\left(\mathrm{cmol}_{\mathrm{c}} \mathrm{dm}^{-3}\right)$ & $\begin{array}{l}0,0-0,2 \\
0,2-0,4\end{array}$ & $\begin{array}{l}9,83 \mathrm{c} \\
8,45 \mathrm{~b}\end{array}$ & $\begin{array}{l}7,59 \mathrm{~b} \\
7,66 \mathrm{~b}\end{array}$ & $\begin{array}{l}6,07 \mathrm{a} \\
5,68 \mathrm{a}\end{array}$ & $\begin{array}{l}6,80 \mathrm{ab} \\
5,94 \mathrm{a}\end{array}$ \\
\hline Soma de bases (SB) $\left(\mathrm{cmol}_{\mathrm{c}} \mathrm{dm}^{-3}\right)$ & $\begin{array}{l}0,0-0,2 \\
0,2-0,4\end{array}$ & $\begin{array}{l}0,47 \mathrm{a} \\
0,21 \mathrm{a}\end{array}$ & $\begin{array}{l}1,86 \mathrm{~b} \\
1,28 \mathrm{c}\end{array}$ & $\begin{array}{l}1,63 \mathrm{~b} \\
1,05 \mathrm{bc}\end{array}$ & $\begin{array}{l}0,61 \mathrm{a} \\
0,50 \mathrm{ab}\end{array}$ \\
\hline CTC efetiva (t) $\left(\mathrm{cmol}_{\mathrm{c}} \mathrm{dm}^{-3}\right)$ & $\begin{array}{l}0,0-0,2 \\
0,2-0,4\end{array}$ & $\begin{array}{l}2,27 \mathrm{~b} \\
2,01 \mathrm{a}\end{array}$ & $\begin{array}{l}2,82 \mathrm{c} \\
2,77 \mathrm{~b}\end{array}$ & $\begin{array}{l}2,23 \mathrm{ab} \\
1,89 \mathrm{a}\end{array}$ & $\begin{array}{l}1,93 \mathrm{a} \\
2,06 \mathrm{a}\end{array}$ \\
\hline CTC total $(\mathrm{T})\left(\mathrm{cmol}_{\mathrm{c}} \mathrm{dm}^{-3}\right)$ & $\begin{array}{l}0,0-0,2 \\
0,2-0,4\end{array}$ & $\begin{array}{r}10,33 \mathrm{c} \\
8,60 \mathrm{~b}\end{array}$ & $\begin{array}{l}9,45 \mathrm{~b} \\
8,99 \mathrm{~b}\end{array}$ & $\begin{array}{l}7,70 \mathrm{a} \\
6,73 \mathrm{~b}\end{array}$ & $\begin{array}{l}7,41 \mathrm{a} \\
6,44 \mathrm{~b}\end{array}$ \\
\hline Saturação por bases V (\%) & $\begin{array}{l}0,0-0,2 \\
0,2-0,4\end{array}$ & $\begin{array}{l}4,6 \mathrm{a} \\
2,5 \mathrm{a}\end{array}$ & $\begin{array}{l}19,7 \mathrm{~b} \\
14,3 \mathrm{~b}\end{array}$ & $\begin{array}{l}21,2 \mathrm{~b} \\
15,8 \mathrm{~b}\end{array}$ & $\begin{array}{l}8,2 \mathrm{a} \\
7,8 \mathrm{a}\end{array}$ \\
\hline Matéria orgânica do solo MOS (dag kg $\left.{ }^{-1}\right)$ & $\begin{array}{l}0,0-0,2 \\
0,2-0,4\end{array}$ & $\begin{array}{l}4,26 \mathrm{c} \\
3,08 \mathrm{c}\end{array}$ & $\begin{array}{l}3,21 \mathrm{~b} \\
2,69 \mathrm{~b}\end{array}$ & $\begin{array}{l}2,75 \mathrm{a} \\
2,29 \mathrm{a}\end{array}$ & $\begin{array}{l}2,82 \mathrm{a} \\
2,29 \mathrm{a}\end{array}$ \\
\hline P-rem $\left(\mathrm{mg} \mathrm{L}^{-1}\right)$ & $\begin{array}{l}0,0-0,2 \\
0,2-0,4\end{array}$ & $\begin{array}{l}26,4 \mathrm{a} \\
23,0 \mathrm{a}\end{array}$ & $\begin{array}{l}31,0 \mathrm{~b} \\
26,1 \mathrm{~b}\end{array}$ & $\begin{array}{l}31,0 \mathrm{~b} \\
27,0 \mathrm{~b}\end{array}$ & $\begin{array}{l}26,7 \mathrm{a} \\
23,7 \mathrm{a}\end{array}$ \\
\hline
\end{tabular}

Valores seguidos da mesma letra não diferem entre si pelo teste de Tukey a $5 \%$.

Os teores de $\mathrm{P}$ disponível foram estatisticamente maiores nas áreas com laranjeira e canavial, nas duas profundidades, enquanto a mata e a pastagem apresentaram os menores valores. Os teores mais elevados de $\mathrm{P}$ disponível nos solos com laranjeira e canavial justificam-se pelo uso de adubações fosfatadas nesses sistemas agrícolas, em que há uma agricultura mais tecnificada, com uso de insumos. Entretanto, não obstante os maiores valores de $\mathrm{P}$ disponível nos solos com laranjeira e canavial, os teores desse elemento em todos os solos avaliados foram classificados como muito baixos, segundo Alvarez V. et al. (1999). Isso evidencia a forte adsorção de P pelo Latossolo avaliado, indicando a necessidade de um manejo adequado da adubação fosfatada para garantir boa produtividade nos Mares de Morros da Zona da Mata mineira.

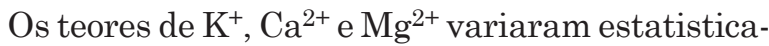
mente entre os diferentes usos do solo; segundo Alvarez V. et al. (1999), a variação dos teores desses nutrientes foi de muito baixo a bom, com os maiores valores ocorrendo nas áreas cultivadas com laranjeira e canavial, e os menores, na mata e pastagem (Quadro 1). Observa-se que 20 anos de uso com pastagem, substi- tuindo o canavial, reduziu os teores de nutrientes no solo, com valores semelhantes aos da mata. Por outro lado, 20 anos de uso com laranjeira tenderam a manter os maiores teores de nutrientes no solo. Esses resultados mostram que o uso e manejo do solo nas áreas com laranjeira e cana tiveram efeito positivo no teor de nutrientes no solo. Por sua vez, a pastagem não alterou os teores de nutrientes no solo em relação à mata, com o agravante de apresentar baixo aporte vegetal, com consequente menor estoque de nutriente na biomassa, indicando que no sistema de pastagem está havendo perda de nutrientes, comprometendo assim a sustentabilidade da produção.

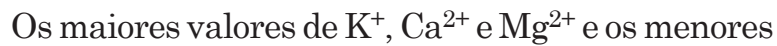
de $\mathrm{Al}^{3+}$ nos sistemas com laranjeira e canavial devemse ao maior nível tecnológico assumido, com realização de correções químicas do solo nesses ambientes, repondo os nutrientes exportados pela produção e, ou, perdidos pela erosão e lixiviação. A pobreza química no solo sob pastagem decorre da ausência de correções químicas do solo, que sofre grande ação exportadora pelo pastoreio do gado, além da facilidade de perda dos nutrientes arrastados pela erosão laminar, devido ao manejo inadequado, que expõe parcialmente o solo. 
Na mata, os teores baixos de nutrientes explicam-se, em parte, pelo fato de que nesse ambiente grande parte dos nutrientes está alocada na vegetação, além da pobreza química do Latossolo e do alto grau de intemperismo dele no ambiente de Mar de Morros (Rezende \& Resende, 1996; Abraão et al., 2000; Santos et al., 2007; Portugal et al., 2008).

Não obstante a melhora química obtida nesses sistemas, observa-se que eles apresentam caráter distrófico (Quadro 1), provavelmente devido à grande exportação de nutrientes pelas culturas, bem como pelas perdas por lixiviação e, ou, erosão. Esses resultados sugerem que a calagem e adubação são práticas necessárias para manter a produtividade nesse solo, já que ele não tem como repor naturalmente esses nutrientes.

A diferença entre CTC efetiva e CTC total foi maior nas áreas com laranjeira e mata (Quadro 1). Esse resultado deve-se ao maior aporte de $\mathrm{C}$ nestas áreas, incrementando o teor de C orgânico do solo, uma importante fonte de carga negativa do solo (Raij, 1981; Rangel \& Silva, 2007; Salton et al., 2008), bem como ao maior $\mathrm{pH}$ na laranjeira, que aumenta as cargas elétricas negativas dependentes de $\mathrm{pH}$ (Fontes et al., 1996; Sousa et al., 2007).

A CTC total $(\mathrm{pH}=7,0)$ reduziu significativamente da área de mata para as áreas com o uso agrícola na camada de 0,0 a $0,2 \mathrm{~m}$ provavelmente devido à redução do teor de C orgânico do solo pela queimada, aração, gradagem, etc., associada às variações nos teores de argila. Entre as áreas com uso agrícola (laranjeira, canavial e pastagem), a área com laranjeira apresentou maior valor de CTC total, e as áreas com canavial e pastagem os menores, acompanhando os teores de matéria orgânica do solo (Quadro 1). Na camada subsuperficial, os valores de CTC total não mostraram variações estatísticas entre os sistemas. Pode-se notar que 20 anos de uso com laranjeira após o canavial resultou em aumento significativo de $18,5 \%$ na CTC total, ao passo que após 20 anos de substituição de canavial por pastagem não houve alteração estatística da CTC total do solo, havendo redução de 3,7 \%.

Houve correlação significativa entre a CTC total e o teor de matéria orgânica (Figura 1), mostrando que parte da variação da CTC é devida à variação no teor de matéria orgânica do solo entre os sistemas avaliados. Canellas et al. (2003), trabalhando com solos sob diferentes manejos, encontraram correlação entre CTC total e o teor de matéria orgânica do solo com $\mathrm{R}^{2}=80 * *$, semelhante ao encontrado neste trabalho $\left(\mathrm{R}^{2}=77^{* *}\right)$; esses autores também encontram maiores valores de CTC total nos manejos que mantiveram e, ou, aumentaram o teor de matéria orgânica do solo. A contribuição da matéria orgânica para a CTC dos solos é importante e foi estimada entre 56 e 82 \% da CTC de solos sob condições tropicais (Raij, 1981), o que favorece a retenção de cátions e diminui as perdas por lixiviação (Rangel \& Silva, 2007; Carneiro et al., 2009). Nos solos de mineralogia predominantemente formada por minerais silicatados do tipo 1:1(caulinita) e óxi-hidroxidos de Fe (hematita e goethita) e $\mathrm{Al}$ (gibbsita), como nos Latossolos brasileiros, a matéria orgânica do solo é a principal geradora de cargas negativas na superfície (Fontes et al., 1996; Sousa et al., 2007), sendo natural a maior capacidade de troca encontrada nas áreas com mata e laranjeira, onde se encontram os maiores teores de matéria orgânica (Quadro 1). Esses resultados evidenciam que o uso e manejo na área com laranjeira, onde não há revolvimento do solo e se mantêm os resíduos das roçadas cobrindo a superfície do solo, aumentaram os teores de matéria orgânica em relação aos demais usos agrícolas e resultaram em melhora na CTC efetiva e total do solo, contribuindo para melhora química do Latossolo sob este sistema.

Os teores de matéria orgânica do solo foram estatisticamente maiores na mata, nas duas profundidades avaliadas, indicando que a retirada da mata e a utilização agrícola do Latossolo reduziram os teores de C orgânico do solo (Quadro 1). Esse resultado está de acordo com Houghton et al. (1991), segundo os quais há um declínio no estoque de matéria orgânica após a conversão de florestas nativas em sistemas agrícolas. Segundo esses autores, essa redução pode ser atribuída ao aumento da erosão do solo, aos processos mais acelerados de mineralização da matéria orgânica do solo e a menores quantidades de aportes orgânicos em sistemas manejados comparativamente às florestas nativas, o que provavelmente está ocorrendo em maior intensidade nas áreas com o uso de canavial e pastagem.

Pode-se notar, nas duas profundidades, que na área com laranjeira os teores de matéria orgânica foram estatisticamente maiores que no canavial e pastagem; estes últimos não se diferenciaram. Isso mostra que 20 anos de uso com laranjeira após retirada do canavial contribuiu para o aumentou significativo dos teores de matéria orgânica no solo. Isso ocorreu devido ao manejo da área com laranjeira, onde foi usado glifosato na linha e roçadeira nas entrelinhas para o controle

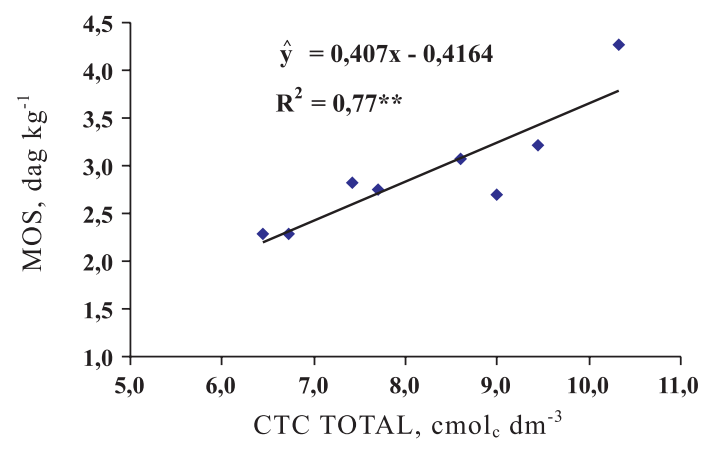

Figura 1. Correlação entre os teores de matéria orgânica do solo (MOS) e a capacidade de troca catiônica total (CTC total) para o Latossolo sob diferentes usos. 
de plantas invasoras, o que garante a cobertura do solo por palhada, bem como não houve aração e gradagem do solo. Segundo Costa et al. (2008), sistemas com manutenção de palhada e sem revolvimento do solo tendem, com o tempo, a apresentar incremento de matéria orgânica no solo.

Por outro lado, 20 anos com a pastagem após canavial não alteraram os teores de matéria orgânica do solo. Isso se explica pelo manejo inadequado da pastagem, com superpastejo e pastoreio contínuo durante todo o ano, sem uso de fertilizantes para repor nutrientes perdidos, o que resulta em menor produção de resíduo vegetal, com consequente menor aporte de material orgânico e maior área de solo exposto, aumentando a erosão e reduzindo o teor de $\mathrm{C}$ no solo. A movimentação e o preparo do solo para o cultivo (aração, gradagem e abertura de sulcos) favorecem as reações de oxidação, por meio do aumento da pressão parcial de $\mathrm{O}_{2}$ e da exposição de novas superfícies para o ataque microbiano, bem como da queima, reduzindo o aporte orgânico para formação de matéria orgânica do solo (Canellas et al., 2003; Rangel \& Silva, 2007; Costa et al., 2008; Carneiro et al., 2009). O balanço líquido desse efeito é a diminuição dos teores de matéria orgânica nos sistemas com preparo de solo mais intenso, como ocorreu no canavial.

Pode-se notar que os atributos químicos $\mathrm{pH}, \mathrm{Al}^{3+}$ teores de nutrientes $\left(\mathrm{K}^{+}, \mathrm{Ca}^{2+}, \mathrm{Mg}^{2+} \mathrm{e} \mathrm{P}\right)$, CTC total, saturação por bases e teor de matéria orgânica do solo mostraram variações entre os sistemas avaliados, indicando que são indicadores sensíveis às mudanças de uso e manejo do solo no ambiente de Mares de Morros da Zona da Mata mineira. Os sistemas com canavial e laranjeira apresentaram o solo com melhor qualidade química, pela reposição dos nutrientes perdidos, bem como pela manutenção de um sistema que mantém a palhada sobre o solo, sem revolvê-lo, como na laranjeira, que elevou o teor de $\mathrm{C}$ do solo e, consequentemente, a CTC total, contribuindo para o incremento na fertilidade do solo.

\section{Atributos físicos}

Com base na análise granulométrica do solo (Quadro 2), pode-se classificá-lo, segundo a Sociedade Brasileira de Ciência do Solo (Santos et al., 2005), como de classe textural argilosa, para todas as áreas e profundidades. Os solos apresentaram relação silte/ argila variando de 0,08 a 0,13 . Os baixos valores de silte indicam que são solos bastante intemperizados, já que a reduzida relação silte/argila, segundo Embrapa (1999), é um indicador do grau de intemperização do solo.

A densidade do solo (DS), na camada de 0,0 a $0,2 \mathrm{~m}$ foi menor na mata, mostrando que o uso antrópico aumentou a compactação do solo, especialmente na pastagem que apresentou o maior valor de DS (Quadro 2). Esses resultados estão de acordo com os obtidos por Islam \& Weil (2000), que constataram um

Quadro 2. Densidade do solo (DS) e das partículas (DP), porosidade total (PT), retenção de água na capacidade de campo (CC) e no ponto de murcha permanente (PM), capacidade de água disponível (CAD), relação $\mathrm{CC} / \mathrm{PT}$ e análise textural, para os diferentes usos e profundidades

\begin{tabular}{|c|c|c|c|c|c|}
\hline Atributo & Profundidade & Mata & Laranja & Cana & Pasto \\
\hline $\mathrm{DS}\left(\mathrm{g} \mathrm{cm}^{-3}\right)$ & $\begin{array}{c}\mathrm{m} \\
0,0-0,2 \\
0,2-0,4\end{array}$ & $\begin{array}{l}1,08 \mathrm{a} \\
1,18 \mathrm{a}\end{array}$ & $\begin{array}{l}1,28 \mathrm{~b} \\
1,16 \mathrm{a}\end{array}$ & $\begin{array}{ll}1,21 & b \\
1,22 & a\end{array}$ & $\begin{array}{l}1,43 \mathrm{c} \\
1,20 \mathrm{a}\end{array}$ \\
\hline $\mathrm{DP}\left(\mathrm{g} \mathrm{cm}^{-3}\right)$ & $\begin{array}{l}0,0-0,2 \\
0,2-0,4\end{array}$ & $\begin{array}{l}2,60 \mathrm{a} \\
2,63 \mathrm{a}\end{array}$ & $\begin{array}{l}2,62 \mathrm{a} \\
2,64 \mathrm{a}\end{array}$ & $\begin{array}{l}2,60 \mathrm{a} \\
2,60 \mathrm{a}\end{array}$ & $\begin{array}{l}2,50 \mathrm{a} \\
2,60 \mathrm{a}\end{array}$ \\
\hline $\mathrm{PT}(\%)$ & $\begin{array}{l}0,0-0,2 \\
0,2-0,4\end{array}$ & $\begin{array}{l}58,7 \mathrm{c} \\
55,2 \mathrm{a}\end{array}$ & $\begin{array}{l}50,7 \mathrm{~b} \\
55,9 \mathrm{a}\end{array}$ & $\begin{array}{l}53,5 \mathrm{~b} \\
53,0 \mathrm{a}\end{array}$ & $\begin{array}{l}45,0, \mathrm{a} \\
52,0, \mathrm{a}\end{array}$ \\
\hline $\mathrm{CC}\left(\mathrm{m}^{3} \mathrm{~m}^{-3}\right)$ & $\begin{array}{l}0,0-0,2 \\
0,2-0,4\end{array}$ & $\begin{array}{ll}0,248 & a \\
0,295 & b\end{array}$ & $\begin{array}{ll}0,320 & b \\
0,290 & a\end{array}$ & $\begin{array}{l}0,327 \mathrm{c} \\
0,354 \mathrm{~d}\end{array}$ & $\begin{array}{ll}0,400 & d \\
0,322 & c\end{array}$ \\
\hline $\mathrm{PM}\left(\mathrm{m}^{3} \mathrm{~m}^{-3}\right)$ & $\begin{array}{l}0,0-0,2 \\
0,2-0,4\end{array}$ & $\begin{array}{ll}0,173 & a \\
0,201 & b\end{array}$ & $\begin{array}{l}0,217 \mathrm{c} \\
0,197 \mathrm{a}\end{array}$ & $\begin{array}{l}0,206 \mathrm{~b} \\
0,207 \mathrm{c}\end{array}$ & $\begin{array}{ll}0,243 & \mathrm{~d} \\
0,223 & \mathrm{~d}\end{array}$ \\
\hline $\mathrm{CAD}\left(\mathrm{m}^{3} \mathrm{~m}^{-3}\right)$ & $\begin{array}{l}0,0-0,2 \\
0,2-0,4\end{array}$ & $\begin{array}{ll}0,076 & \mathrm{a} \\
0,094 & \mathrm{a}\end{array}$ & $\begin{array}{ll}0,103 & b \\
0,093 & a\end{array}$ & $\begin{array}{ll}0,121 & c \\
0,146 & c\end{array}$ & $\begin{array}{ll}0,157 & d \\
0,099 & b\end{array}$ \\
\hline $\mathrm{CC} / \mathrm{PT}$ & $\begin{array}{l}0,0-0,2 \\
0,2-0,4\end{array}$ & $\begin{array}{l}0,42 \text { a } \\
0,54 \text { a }\end{array}$ & $\begin{array}{l}0,63 \mathrm{~b} \\
0,52 \mathrm{a}\end{array}$ & $\begin{array}{l}0,61 \mathrm{~b} \\
0,66 \mathrm{c}\end{array}$ & $\begin{array}{l}0,89 \mathrm{c} \\
0,61 \mathrm{~b}\end{array}$ \\
\hline Areia $\left(\mathrm{g} \mathrm{kg}^{-1}\right)$ & $\begin{array}{l}0,0-0,2 \\
0,2-0,4\end{array}$ & $\begin{array}{l}470 \mathrm{c} \\
400 \mathrm{~b}\end{array}$ & $\begin{array}{l}390 \mathrm{a} \\
390 \mathrm{~b}\end{array}$ & $\begin{array}{l}430 \mathrm{~b} \\
390 \mathrm{~b}\end{array}$ & $\begin{array}{l}380 \mathrm{a} \\
350 \mathrm{a}\end{array}$ \\
\hline Silte $\left(\mathrm{g} \mathrm{kg}^{-1}\right)$ & $\begin{array}{l}0,0-0,2 \\
0,2-0,4\end{array}$ & $\begin{array}{l}40 \mathrm{a} \\
70 \mathrm{a}\end{array}$ & $\begin{array}{l}70 \mathrm{a} \\
70 \mathrm{a}\end{array}$ & $\begin{array}{l}60 \mathrm{a} \\
40 \mathrm{a}\end{array}$ & $\begin{array}{l}60 \mathrm{a} \\
70 \mathrm{a}\end{array}$ \\
\hline Argila ( $\mathrm{g} \mathrm{kg}^{-1}$ ) & $\begin{array}{l}0,0-0,2 \\
0,2-0,4\end{array}$ & $\begin{array}{l}490 \mathrm{a} \\
530 \mathrm{a}\end{array}$ & $\begin{array}{l}540 \mathrm{~b} \\
540 \mathrm{a}\end{array}$ & $\begin{array}{rl}51 & \mathrm{a} \\
570 & \mathrm{~b}\end{array}$ & $\begin{array}{l}560 \mathrm{~b} \\
580 \mathrm{~b}\end{array}$ \\
\hline
\end{tabular}

Valores seguidos da mesma letra não diferem entre si pelo teste de Tukey a $5 \%$. 
valor médio da DS significativamente maior em áreas cultivadas, comparadas com o solo sob floresta. Também Silva \& Ribeiro (1992) obtiveram resultados similares comparando solo cultivado com cana e sob mata nativa. Sanches et al. (1999) constataram que, independentemente da posição de amostragem, seja na linha ou entrelinha da cultura da laranjeira, a DS foi maior do que no solo sob mata. Somente o sistema com pastagem $\left(1,43 \mathrm{~kg} \mathrm{dm}^{-3}\right)$ apresentou valor de DS superior a $1,40 \mathrm{~kg} \mathrm{dm}^{-3}$, considerado por Klein \& Câmara (2007) como prejudicial às plantas para Latossolos argilosos, indicando a pior condição física do solo na pastagem, em detrimento dos sistemas com laranjeira $\left(1,28 \mathrm{~kg} \mathrm{dm}^{-3}\right)$ e cana $\left(1,21 \mathrm{~kg} \mathrm{dm}^{-3}\right)$, em que os valores de DS não foram críticos.

Entre os sistemas agrícolas, pode-se notar que laranjeira e canavial não diferiram significativamente quanto a DS, apresentando valores intermediários entre a mata e a pastagem (Quadro 2). Esses resultados indicam que, em superfície, a laranjeira manteve a DS semelhante à do canavial, ao passo que na pastagem houve aumento da DS de 18,2\% em relação ao canavial, e de $32,4 \%$ em relação à mata. De 0,2 a 0,4 m não foram observadas alterações estatísticas na DS, indicando que o uso agrícola causou compactação apenas de 0,0 a 0,2 m.

$\mathrm{Na}$ laranjeira, houve compactação do solo em relação à mata devido ao tráfego de máquinas. Segundo Lima et al. (2004), a compactação do solo na produção de laranja é condicionada por fatores externos, especificamente pelo tipo, pela intensidade e pela frequência da pressão aplicada por máquinas agrícolas, e fatores internos, como textura. Em áreas citrícolas, em um ano agrícola, é comum a frequência de 15 passadas de trator para realização de operações como adubação, pulverização, capina, entre outras (Stolf, 1987). Mesmo com o uso de máquinas, o valor de DS na laranjeira foi estatisticamente semelhante ao do canavial, onde há o revolvimento do solo, provavelmente devido ao manejo com manutenção de restos vegetais sobre o solo e ao não revolvimento deste, bem como pelo maior teor de matéria orgânica do solo em relação ao canavial, incrementando a estruturação do solo (Castro Filho et al., 1998; Salton et al., 2008).

$\mathrm{Na}$ pastagem, o valor de DS elevado deve-se ao alto grau de pisoteio do gado com pastejo contínuo e superlotação. Também a degradação da pastagem, com presença de solo exposto (estimativa de $30 \%$ de solo exposto), favorece ciclos de umedecimento e secagem, que podem provocar o adensamento do solo (Oliveira et al., 1996). Segundo Leão et al. (2004), o pisoteio animal em toda a superfície e, às vezes, repetidamente no mesmo local promove consideráveis alterações físicas no solo, especialmente quando este apresentar umidade alta. Na literatura, são mencionados valores de pressão que variam entre 0,25 e 0,49 MPa para bovinos de 100 a $500 \mathrm{~kg}$, podendo atingir a profundidade de 5 a $10 \mathrm{~cm}$ (Proffitt et al., 1993).
A densidade de partículas não se modificou entre os sistemas avaliados e as profundidades (Quadro 2). $\mathrm{Na}$ profundidade de 0,0 a $0,2 \mathrm{~m}$, a porosidade total (PT) foi maior na mata em relação aos usos antrópicos, e os sistemas com laranjeira e cana apresentaram PT significativamente maior que a pastagem. Somente a pastagem na superfície $(0,0$ a $0,2 \mathrm{~m})$ apresentou valor menor que $50 \%$, considerado como a percentagem de poros adequada para que um solo tenha boa infiltração e retenção de água, aeração, crescimento radicular e desenvolvimento de atividade biológica (Kiehl, 1979; Silva et al., 2000; Carneiro et al., 2009).

No tocante às características de retenção de água no solo, na superfície, as características CC, PM, CAD e CC/PT foram menores para mata, seguidas por laranja e cana e, por fim, pela pastagem, apresentando valores maiores (Quadro 2). A quantidade de água retida pelo solo, em equilíbrio com determinado potencial, é função do tamanho e do volume dos poros e da superfície específica das partículas da fase sólida (Baver, 1956). Desse modo, a maior retenção de água nos solos com sistemas agrícolas deve-se ao aumento da compactação, com redução de macroporos e aumento de microporos, gerando poros com dimensões e geometria que favorecem a retenção de água por capilaridade. Os maiores valores de densidade do solo (Quadro 2) e resistência do solo à penetração (Figura 2) nos usos agrícolas, sobretudo na pastagem, indicam que há relação entre o aumento da compactação pelo uso do solo e a retenção de água nele.

A relação $\mathrm{CC} / \mathrm{PT}$ ideal é de 0,66 para que ocorra boa atividade microbiana, capaz de mineralizar os restos culturais e disponibilizar nitrogênio para as plantas (Reynolds et al., 2002). Os sistemas de laranjeira e canavial têm valores próximos do ideal, indicando boa relação para conteúdo de água na $\mathrm{CC}$, ao passo que na pastagem o valor bastante elevado pode levar a uma aeração deficiente quando o solo estiver próximo à $\mathrm{CC}$, dificultando a atividade microbiana e a respiração radicular das plantas, conforme citado por Reynolds et al. (2002).

A resistência do solo à penetração $(\mathrm{RP})$ mostrou valores significativamente menores para mata e maiores para pastagem, e intermediários e próximos para laranjeira e canavial, até a profundidade de $0,2 \mathrm{~m}$ (Figura 2). A partir dessa profundidade não houve diferença entre os sistemas quanto à RP.

A pastagem apresentou maior RP, o que está relacionado à compactação observada nesse sistema, com redução de macroporos, juntamente com o sistema radicular denso da braquiária, que preenche grande proporção desses macroporos, aumentando a rigidez do sistema (Pedrotti et al., 2001; Carneiro et al., 2009), além da baixa umidade do solo no momento da avaliação. Imhoff et al. (2000), trabalhando com pastagem de capim-colonião, que também tem sistema radicular denso, encontraram valores de $\mathrm{RP}$ de 
RESISTÊNCIA DO SOLO, MPa

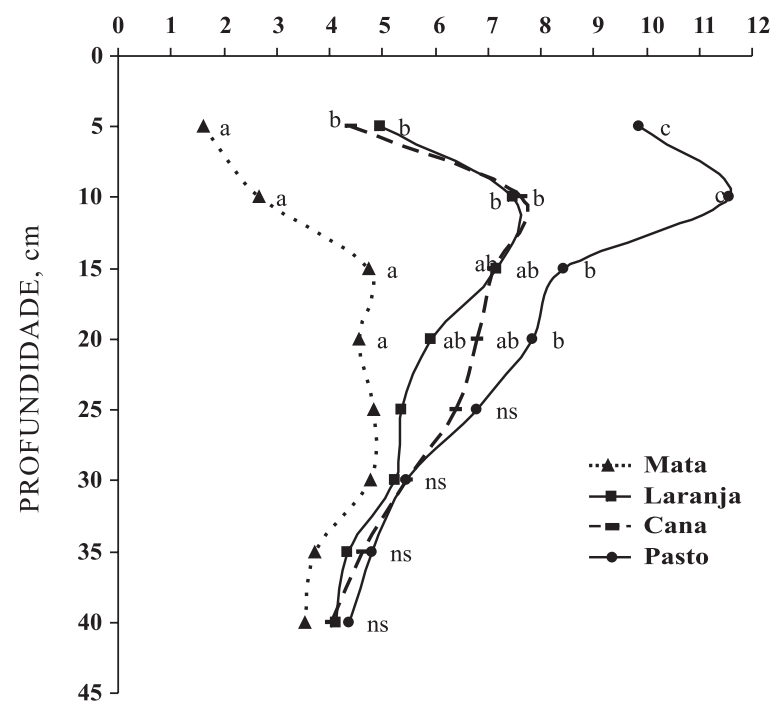

Figura 2. Resistência do solo à penetração em Latossolo sob mata, laranja, cana e pastagem, com umidade do solo de 0,$165 ; 0,153 ; 0,199$; e $0,135 \mathrm{~kg} \mathrm{~kg}^{-1}$, respectivamente. Médias seguidas pela mesma letra, em cada profundidade, não diferem estatisticamente entre si pelo teste de Tukey a $5 \%$.

$10 \mathrm{MPa}$ em solo com DS de $1,5 \mathrm{~g} \mathrm{~cm}^{-3}$ e umidade volumétrica de $0,200 \mathrm{~m}^{3} \mathrm{~m}^{-3}$. Os sistemas apresentaram maior $\mathrm{RP}$ a $0,1 \mathrm{~m}$, e os valores de $\mathrm{RP}$ para os usos agrícolas indicam que o sistema radicular das culturas vem encontrando dificuldade de crescimento, embora todos os ambientes tenham apresentado umidade do solo muito baixa no momento da avaliação, aproximando-se do ponto de murcha (PM), especialmente na pastagem, o que contribuiu para os elevados valores de RP. Os níveis críticos de resistência do solo para o crescimento das plantas variam com o tipo de solo e com a espécie cultivada, sendo difícil estabelecer limites críticos, já que variam com a DS e a umidade do solo. Merotto Jr. \& Mundstock (1999) e Canarache (1990) indicaram valores de 3,5 e $5 \mathrm{MPa}$, respectivamente, como o limite crítico de RP, porém muitos pesquisadores utilizam $2 \mathrm{MPa}$ como o limite crítico, conforme Taylor et al. (1966). Considerando os valores de RP, pode-se notar que laranjeira e canavial apresentaram níveis de degradação física intermediários, ao passo que na pastagem observou-se nível mais avançado de degradação física, indicando que o uso e manejo adotados nas áreas com laranjeira e canavial preservam mais as condições físicas.

A análise de estabilidade de agregados mostra que os sistemas com laranjeira, cana e pastagem reduziram consideravelmente a proporção de agregados estáveis em água na classe maior que $2 \mathrm{~mm}$, em relação à mata (Figura 3 ). Na camada de 0,0 a 0,2 m esses sistemas diferiram significativamente entre si. De 0,2 a 0,4 m, somente a laranjeira apresentou percentagem de agregados estáveis em água semelhante à da mata. Essa análise mostra que há menor resistência dos agregados e consequente menor estruturação na superfície dos solos com laranjeira, canavial e pastagem em relação à mata. Este resultado é indesejável, visto que a estrutura tem grande influência nos ciclos de carbono e de nutrientes, na capacidade de receber, estocar e transmitir água, na difusão de gases, na penetração das raízes e na capacidade de resistir à erosão, que são fatores determinantes para o crescimento das plantas (Salton et al., 2008).

A menor estabilidade de agregados nos sistema com laranjeira, cana e pastagem deve-se aos menores teores de matéria orgânica nesses solos em relação à mata, já que esta é reconhecidamente um agente agregante (Castro Filho et al.,1998; Salton et al., 2008), bem como ao fato de esses sistemas estarem mais sujeitos à ocorrência de ciclos de umedecimento e secagem, o que diminui a estabilidade de agregados dos solos (Oliveira et al., 1996), e, ainda, à desestruturação mecânica ocasionada por implementos agrícolas e pelo pisoteio de gado.

Os atributos físicos DS, PT, CC, PM, CAD, CC/ $\mathrm{PT}, \mathrm{RP}$ e estabilidade de agregados foram indicadores físicos da qualidade do solo sensíveis às mudanças no seu uso e manejo. Esses indicadores mostraram melhor qualidade física do solo nos sistemas com laranjeira e canavial, em detrimento do sistema com pastagem. De maneira geral, os resultados indicam que no ambiente de Mares de Morros o uso e o manejo inadequado do solo - como no sistema de pastagem avaliado, largamente utilizado na região - provocam a perda da sua qualidade química e física.

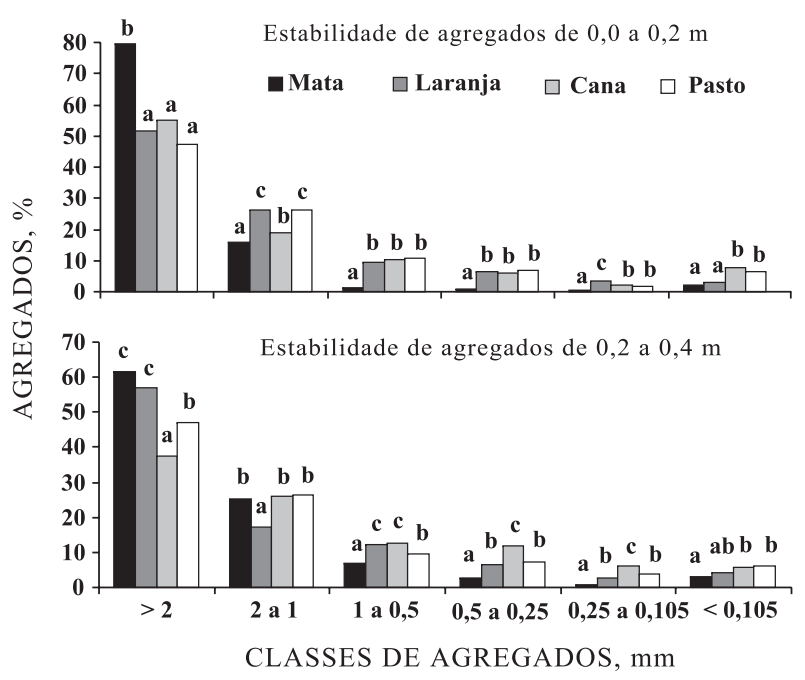

Figura 3. Distribuição e estabilidade de agregados em água do Latossolo sob diferentes usos. Médias seguidas da mesma letra em cada classe não diferem estatisticamente entre si pelo teste de Tukey a $5 \%$. 


\section{CONCLUSÕES}

1. O uso antrópico do Latossolo alterou suas propriedades físicas e químicas em relação à mata. Os sistemas agrícolas com laranjeira e canavial apresentaram valores de densidade do solo, porosidade total, retenção de água, relação capacidade de campo/ porosidade total e resistência do solo à penetração intermediários entre a mata e a pastagem; redução dos teores de matéria orgânica do solo; e melhora na condição química deste pelo incremento no teor de nutrientes e redução da acidez e do teor de $\mathrm{Al}^{3+}$ no complexo de troca. O sistema agrícola com pastagem mostrou degradação física mais avançada, evidenciada pelo aumento da densidade do solo e resistência à penetração, e redução da porosidade total, da estabilidade de agregados e do teor de matéria orgânica do solo, além de manter a condição química semelhante à da mata, com alta acidez e teor de $\mathrm{Al}^{3+}$ trocável $\mathrm{e}$ baixos teores de nutrientes.

2. A substituição do canavial por laranjeira manteve e, ou, melhorou as condições químicas e físicas do Latossolo, ao passo que a substituição do canavial por pastagem piorou as condições químicas e físicas do Latossolo.

\section{LITERATURA CITADA}

ABRAHÃO, W.A.P.; FERNANDES FILHO, E.I.; MIRANDA, L.H.F. \& RAMILO, G.A.I. Levantamento de solos e aptidão agrícola das terras do município de Ubá - MG. Viçosa, MG, Universidade Federal de Viçosa/Prefeitura de Ubá, 2000. 136p.

AB'SABER, A.N. Províncias geológicas e domínios morfoclimáticos no Brasil. Geomorfologia, 20:1-26, 1970.

ALVAREZ V., V.H.; DIAS, L.E. \& OLIVEIRA, J.A. Determinação de fósforo remanescente. Viçosa, MG, Universidade Federal de Viçosa, 1993. 10p. (Não Publicado)

ALVAREZ V., V.H.; NOVAIS, R.F.; BARROS, N.F.; CANTARUTI, R.B. \& LOPES, A.S. Interpretação dos resultados das análises de solos. In: RIBEIRO, A.C.; GUIMARÃES, P.T.G. \& ALVAREZ V., V.H. Recomendações para o uso de corretivos e fertilizantes em Minas Gerais. Viçosa, MG, Universidade Federal de Viçosa, 1999. 359p.

BAVER, L.D. Soil physics. 3.ed. New York, John Wiley \& Sons, 1956. 489p.

CANARACHE, A. Penet - a generalized semi-empirical model estimating soil resistance to penetration. Soil Tillage Res., 16:51-70, 1990 .

CANELLAS, L.P.; VELLOSO, A.C.X.; MARCIANO, C.R.; RAMALHO, J.F.G.P.; RUMJANEK, V.M.; REZENDE C.E. \& SANTOS, G.A. Propriedades químicas de um Cambissolo cultivado com cana-de-açúcar, com preservação do palhiço e adição de vinhaça por longo tempo. R. Bras. Ci. Solo, 27:935-944, 2003.
CARNEIRO, M.A.C.; SOUZA, E.D.; REIS, E.F., PEREIRA, H.S. \& AZEVEDO, W.C. Atributos físicos, químicos e biológicos de solo de cerrado sob diferentes sistemas de uso e manejo. R. Bras. Ci. Solo, 33:147-157, 2009.

CASTRO FILHO, C.; MUZILLI, O. \& PODANOSCHI, A.L. Estabilidade dos agregados e sua relação com o teor de carbono orgânico em um Latossolo Roxo distrófico, em função de sistema de plantio, rotação de cultura e métodos de preparo das amostras. R. Bras. Ci. Solo, 22:527-538, 1998.

COSTA, F.S.; BAYER, C.; ZANATTA, J.A. \& MIELNICZUK, J. Estoque de carbono orgânico no solo e emissões de dióxido de carbono influenciadas por sistemas de manejo no sul do Brasil. R. Bras. Ci. Solo, 32:323-332, 2008.

EMPRESA BRASILEIRA DE PESQUISA AGROPECUÁRIA EMBRAPA. Serviço Nacional de Levantamento e Conservação do Solo. Manual de métodos de análise do solo. Rio de Janeiro, 1997. 212p.

EMPRESA BRASILEIRA DE PESQUISA AGROPECUÁRIA EMBRAPA. Centro Nacional Pesquisa de Solos. Sistema brasileiro de classificação de solos. Brasília, 1999. 412p.

FONTES, M.P.F.; CAMARGO, O.A. \& SPOSITO, G. Eletroquímica das partículas coloidais e sua relação com a mineralogia de solos altamente intemperizados. Sci. Agríc., 58:627-646,2001.

HAYNES, R.J. \& NAIDU, R. Influence of lime, fertilizer and manure applications on soil organic matter content and soil physical conditions: A review. Nutr. Cyclic Agroecosyst., 51:123-137, 1998

HOUGHTON, R.A.; SKOLE, D.L. \& FEFKOWITZ, D.S. Changes in the landscape of Latin American between 1850 and 1985. II Net release of CO2 to the atmosfhere. For. Ecol. Manag., 38:173-199, 1991.

IMHOFF, S.; SILVA, A.P. \& TORMENA, C.A. Aplicações da curva de resistência no controle da qualidade física de um solo sob pastagem. Pesq. Agropec. Bras., 35:1493-1500, 2000 .

ISLAM, K.R. \& WEIL, R.R. Land use effects on soil quality in a tropical forest ecosystem of Banglasdesh. Agr. Ecos. Environ., 79:9-19, 2000.

JOSÉ, O. Visconde do Rio Branco: Terra-Povo-História. Belo Horizonte, Imprensa Oficial de Minas Gerais, 1982. 565p.

KIEHL, E.J. Manual de edafologia - Relações solo-planta. São Paulo, Agronômica Ceres, 1979. 262p.

KLEIN, V.A. \& CAMARA, R.K. Rendimento de soja e intervalo hídrico ótimo em Latossolo Vermelho sob plantio direto escarificado. R. Bras. Ci. Solo, 31:221-227, 2007.

LEÃO, T.P.; SILVA, A.P.; MACEDO, M.C.M.; IMOFF, S. \& EUCLIIDES, V.P.B. Intervalo hídrico ótimo na avaliação de sistemas de pastejo contínuo e rotacionado. R. Bras. Ci. Solo, 28:415-423, 2004.

LIMA, C.L.R.; SILVA, A.P.; IMHOFF, S.; LIMA, H.V. \& LEÃO, T.P. Heterogeneidade da compactação de um Latossolo Vermelho-Amarelo sob pomar de laranja. R. Bras. Ci. Solo, 28:409-414, 2004. 
MEROTTO Jr., A. \& MUNDSTOCK, C.M. Wheat root growth as affected by soil strength. R. Bras. Ci. Solo, 23:135-143, 1999.

OLIVEIRA, T.S.; COSTA, L.M.; REGAZZI, A.J. \& FIGUEIREDO, M.S. Efeitos dos ciclos de umedecimento e secagem sobre a estabilidade de agregados em água de quatro Latossolos brasileiros. R. Bras. Ci. Solo, 20:509. $515,1996$.

PEDROTTI, A.; PAULETTO, E.A. \& GOMES, A.S. Resistência mecânica à penetração de um Planossolo submetido a diferentes sistemas de cultivo. R. Bras. Ci. Solo, 28:477484, 2004.

PORTUGAL, A.F.; COSTA, O.V.D.; COSTA, L.M. \& SANTOS, B.C.M. Atributos químicos e físicos de um Cambissolo Háplico tb distrófico sob diferentes usos na Zona da Mata mineira. R. Bras. Ci. Solo, 32:249-258, 2008.

PROFFIT, A.P.B.; BENDOTTI, S.; HOWELL, M.R. \& EASTHAM, J. The effect of sheep trampling and grazing on soil physical properties and pasture growth for a RedBrown Earth. Austr. J. Agr. Res., 44:317-331, 1993.

RAIJ, B.van. Mecanismos de interação entre solos e nutrientes. In: RAIJ, B.van, ed. Avaliação da fertilidade do solo. Piracicaba, Instituto da Potassa e Fosfato, 1981. p.17-31.

RANGEL, O.J.P. \& SILVA, C.A. Estoques de carbono e nitrogênio e frações orgânicas de Latossolo submetido a diferentes sistemas de uso e manejo. R. Bras. Ci. Solo, 31:1609-1623, 2007.

REICHARDT, K. Capacidade de campo. R. Bras. Ci. Solo, 12:211-216, 1988.

REYNOLDS, W.D.; BOWMAN, B.T.; DRURY, C.F.; TAN, C.S. \& LU, X. Indicator of good soil physical quality: Density and storage parameters. Geoderma, 110:131-146, 2002.

REZENDE, S.B. \& RESENDE, M. Solos dos mares de morros: Ocupação e uso. In: ALVAREZ V., V.H., FONTES, L.E.F. \& FONTES, M.P.F., eds. Os solos nos grandes domínios morfoclimáticos do Brasil e o desenvolvimento sustentável. Viçosa, MG, Sociedade Brasileira de Ciência do Solo/Universidade Federal de Viçosa, 1996. p.261-289.
SANCHES, A.C.; SIVLA, A.P.; TORMENA, C.A. \& RIGOLIN, A.T. Impacto do cultivo de citros em propriedades químicas, densidade do solo e atividade microbiana de um Podzólico Vermelho-Amarelo. R. Bras. Ci. Solo, 23:91-99, 1999.

SANTOS, G.V.; DIAS, H.C.T.; SILVA, A.P.S. \& MACEDO, M.N.C. Análise hidrológica e socioambiental da bacia hidrográfica do córrego Romão dos Reis, Viçosa-MG. R. Árvore, 31:931-940, 2007.

SANTOS, R.D.; LEMOS, R.C.; SANTOS, H.G.; KER, J.C. \& ANJOS, L.H.C. Manual de descrição e coleta de solo no campo. 5.ed. Viçosa, MG, Universidade Federal de Viçosa, 2005. 91p.

SALTON, J.C.; MIELNICZUK, J.; BAYER, C.; BOENI, M.; CONCEIÇÃO, P.C.; FABRÍCIO, A.C.; MACEDO, M.C.M. \& BROCH, D.L. Agregação e estabilidade de agregados do solo em sistemas agropecuários em Mato Grosso do Sul. R. Bras. Ci. Solo, 32:11-21, 2008.

SEBRAE - Diagnóstico da fruticultura de Minas Gerais. Belo Horizonte, 2001. 202p.

SILVA, M.S.L. \& RIBEIRO, M.R. Influência do cultivo contínuo da cana-de-açúcar em propriedades morfológicas e físicas de solos argilosos de tabuleiro no Estado de Alagoas. R. Bras. Ci. Solo, 16:397-402, 1992.

STOLF, R. A compactação do solo e perspectivas da subsolagem em citrus. Laranja, 2:283-308, 1987.

STOLF, R. Teoria e teste experimental de fórmulas de transformação dos dados de penetrômetro de impactos em resistência do solo. R. Bras. Ci. Solo,15:229-235, 1991.

SOUZA, D.M.G.; MIRANDA, L.N. \& OLIVEIRA, S.A. Acidez do solo e sua correção. In: NOVAIS, R.F.; ALVAREZ V., V.H.; BARROS, N.F.; FONTES, R.L.F.; CANTARUTTI, R.B. \& NEVES, J.C.L. Fertilidade do solo. Viçosa, MG, Sociedade Brasileira de Ciência do Solo, 2007. 991p.

TAYLOR, H.M.; ROBERTSON, G.M. \& PARKER, J.J. Soil strength root penetration relations for medium to coarse textured soil materials. Soil Sci., 102:18-22, 1966. 